\title{
Amritpal Singh Saroya: Contemporary Phytomedicines
}

\author{
John Edmondson ${ }^{1}$
}

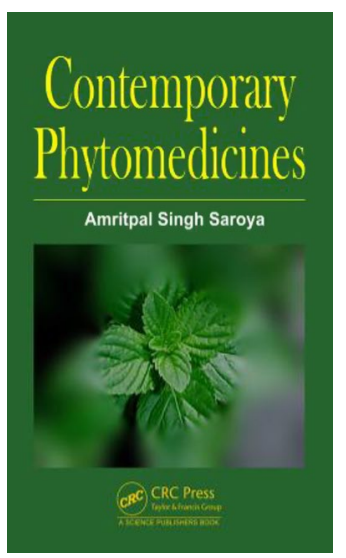

Bibliography

Contemporary Phytomedicines

Amritpal Singh Saroya

CRC Press, Boca Raton, FL, USA, 2017,

pp 366

ISBN 978-1-4987-7355-3

GBP 114.00, USD 179.95

This book has been conceived as a bridge between traditional and modern herbal medicine. Its 33 chapters and 9 annexes range over a wide field of topics, including economics, epidemiology, genomics and clinical research. A sizeable chunk of the second section focuses on bioactives derived from Withania somnifera, and various classes of pharmaceuticals including steroidal alkaloids, phytoecdysteroids and guggulsterones are described in separate chapters. The first section of the book covers industrial aspects, and there is a chapter on clinical research in Ayurveda. Symphytum-based herbal products are also discussed in detail.

The book has been designed to be useful to students, and it contains lists of acronyms and abbreviations, definitions of pharmacobotanical terms, and a herbal glossary in the preliminary materials. The index is woefully deficient,

John Edmondson

chromatographia@springer.com

1 Royal Botanic Gardens, Richmond, UK as it fails to list the scientific names of many if not most of the plants whose compounds are discussed in detail in Part B (Bioactives from Phytomedicine). Another curious error is the conflation of generic and specific epithets of plant names into a single word, with authorities included or omitted at random; this points to an absence of subediting, throwing doubt on whether there was sufficient quality control during its production.

A random sample of botanical descriptions shows that some of these were copied and pasted directly from accounts published in the Flora of China; while I have not troubled to check the text extensively, I would surmise that this may prove to be the method by which much of the descriptive material was assembled.

Mis-spellings such as "Native to Isreal" (sic) should have been corrected at proof stage. Howlers such as "Felix Hoffman isolated aspirin from willow bark" (p. 7) should not have been allowed in print; aspirin is the acetyl (synthetic) variant (precursor and metabolite) of salicylic acid and does not occur in nature. In conclusion, this book appears unreliable in that the knowledge it contains has been assembled rather than filtered through the author's expertise. 